\section{A simple trick to excise the carpal bones during proximal row carpectomy}

Sir,

Proximal row carpectomy (PRC) is a common surgery done in the hand surgery practice. It involves excising the scaphoid, lunate and triquetrum bones. It is a common motion preserving operation done in conditions such as scapholunate advanced collapse (wrist), instability of the wrist, scaphoid non-union advanced collapse (wrist), Kienbock's disease and as a part of total wrist fusion in conditions such as rheumatoid arthritis.

It remains one of the time-tested surgeries, which is quick, simple and effective with early return to activities for the patient. Its effectiveness has been proven in many long-term studies. ${ }^{[1]}$ However, Green quoted, "PRC is not an elegant operation." ${ }^{[2]}$ Truly so, as the piecemeal excision of the carpal bones which is commonly practiced is not elegant. It is time-consuming, there is chance of leaving some bone chips behind and the removal of the most volar part of the lunate and scaphoid can be very difficult.

Having faced these difficulties, we started using "Schanz pin" as a joystick to manipulate the carpal bones and help in easy excision of the carpal bones. Schanz pin is easily available instrument in all the operation theatres; therefore, no special instruments are required.

Operative technique - The wrist joint is opened by a standard dorsal approach. The capitate and the lunate articular surface of the radius are inspected to confirm the possibility of PRC. The scapholunate and lunotriquetral ligaments are excised. The dorsal cortex of the lunate is first nibbled to expose cancellous bone, and then a $3 \mathrm{~mm}$ Schanz pin is passed into the lunate. The pin should be directed toward the body of the lunate to avoid damage to the articular surface of the capitate. The
Schanz pin is used to manipulate the lunate and release all its soft-tissue attachments allowing it to be excised as a single piece [Figure 1a]. Similarly, the Schanz pin is put in the triquetrum and scaphoid and both the bones are excised in a single piece making the surgery elegant, easy and fast [Figure 1b]. We observed a reduction in operative time of 10-15 min when using this technique as opposed to the piecemeal excision.

PRC is a commonly performed and time tested surgical technique for various wrist pathologies. The simple technical tip described here not only makes the surgery easy and quick but also makes it look elegant!

Hence, we report this small technical tip for wider use.

\section{Financial support and sponsorship}

Nil.

\section{Conflicts of interest}

There are no conflicts of interest.

\section{Warid Altaf, Praveen Bhardwaj,} S. Raja Sabapathy, Baktash A. Haseeb

Department of Plastic, Hand \& Reconstructive Microsurgery and Burns, Ganga Hospital, Coimbatore, Tamil Nadu, India

Address for correspondence: Dr. Praveen Bhardwaj Consultant- Hand Surgery, Department of Plastic, Hand \& Reconstructive Microsurgery and Burns, Ganga Hospital, Coimbatore, Tamilnadu, India E-mail-drpb23@gmail.com

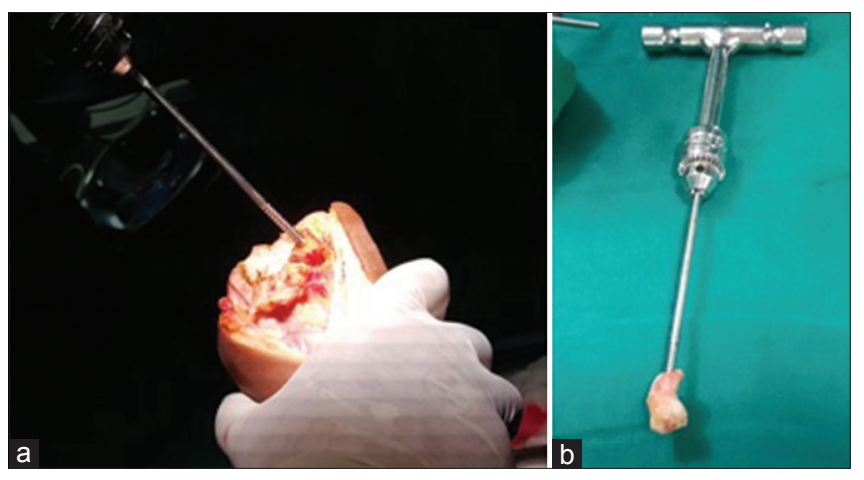

Figure 1: (a) Schanz pin in place in the carpal bone which is being manipulated to cut all the soft-tissue attachments around it. (b) The whole scaphoid has been excised as a single piece 


\section{REFERENCES}

1. Wall LB, Didonna ML, Kiefhaber TR, Stern PJ. Proximal row carpectomy: Minimum 20-year follow-up. J Hand Surg Am 2013;38:1498-504.

2. Green DP. Proximal row carpectomy. Hand Clin 1987;3:163-8.

This is an open access journal, and articles are distributed under the terms of the Creative Commons Attribution-NonCommercial-ShareAlike 4.0 License, which allows others to remix, tweak, and build upon the work non-commercially, as long as appropriate credit is given and the new creations are licensed under the identical terms.

\begin{tabular}{|l|l|}
\hline \multicolumn{2}{|c|}{ Access this article online } \\
\hline Quick Response Code: & Website: \\
\hline $\mathbf{n}$ & www.ijps.org \\
\cline { 2 - 2 } & DOI: \\
\hline
\end{tabular}

How to cite this article: Altaf W, Bhardwaj $P$, Sabapathy SR, Haseeb BA. A simple trick to excise the carpal bones during proximal row carpectomy. Indian J Plast Surg 2018;51:101-2.

(C) 2018 Indian Journal of Plastic Surgery | Published by Wolters Kluwer - Medknow 